\title{
Performance optimization for a variable throat ejector in a solar refrigeration system
}

\author{
R.H. Yen ${ }^{a, *}$, B.J. Huang ${ }^{a}$, C.Y. Chen ${ }^{b}$, T.Y. Shiu ${ }^{a}$, C.W. Cheng ${ }^{a}$, S.S. Chen ${ }^{a}$, \\ K. Shestopalov ${ }^{a}$ \\ ${ }^{a}$ Department of Mechanical Engineering, National Taiwan University, Taipei, Taiwan \\ ${ }^{\mathrm{b}}$ Department of Materials Science and Engineering, National Cheng Kung University, Tainan, Taiwan
}

\section{A R T I C L E I N F O}

Article history:

Received 12 June 2012

Received in revised form

4 April 2013

Accepted 5 April 2013

Available online 23 April 2013

Keywords:

Performance

Solar vapor ejector

Refrigeration system

Variable throat

\begin{abstract}
A B S T R A C T
In a solar vapor ejector refrigeration system, the solar heat supply may vary because of variations in solar irradiation intensity, making it difficult to maintain a steady generator temperature. To improve ejector performance, this study proposes a variable throat ejector (VTEJ) and analyzes its performance using CFD simulations. The following conclusions can be drawn. An ejector with a greater throat area and larger solar collector allows a wider operating range of generator temperatures, but may be overdesigned and expensive. Conversely, decreasing the throat area limits the operating range of generator temperatures. Thus the ejector with a fixed throat area may be unsuitable to use solar energy as a heat source. For a VTEJ, this study derives a curve-fitting relationship between the optimum throat area ratio and the operating temperatures. Using this relationship to adjust the throat area ratio, the ejector can consistently achieve optimal and stable performances under a varying solar heat supply.
\end{abstract}

(c) 2013 Elsevier Ltd and IIR. All rights reserved.

\section{Optimisation de la performance d'un éjecteur à tuyère variable dans un système frigorifique solaire}

Mots clés : performance ; système solaire à éjecteur ; système frigorifique ; tuyère variable

\section{Introduction}

In an ordinary vapor ejector refrigeration system, the refrigerant passes through the solar collector and then leaves as vapor. In addition to receiving heat from the sun, the collector also acts as the vapor generator for the refrigeration system. However, the amount of solar heat supply to the collector may fluctuate because of variations in the intensity of solar irradiation, making it difficult to maintain a steady generator temperature. The evaporator and condenser temperatures may also fluctuate during system operation.

The performance of an ejector-refrigeration system depends on the ejector geometry and the operating conditions. The ejector performance (i.e., entrainment ratio $\left(E_{\mathrm{m}}\right)$, coefficient of performance (COP), and critical condenser temperature $\left(T_{\mathrm{cr}}\right)$ ) can be varied by changing the operating

\footnotetext{
* Corresponding author. Tel.: +886 22363 2137; fax: + 886223631755.

E-mail address: rhyen@ntu.edu.tw (R.H. Yen). 


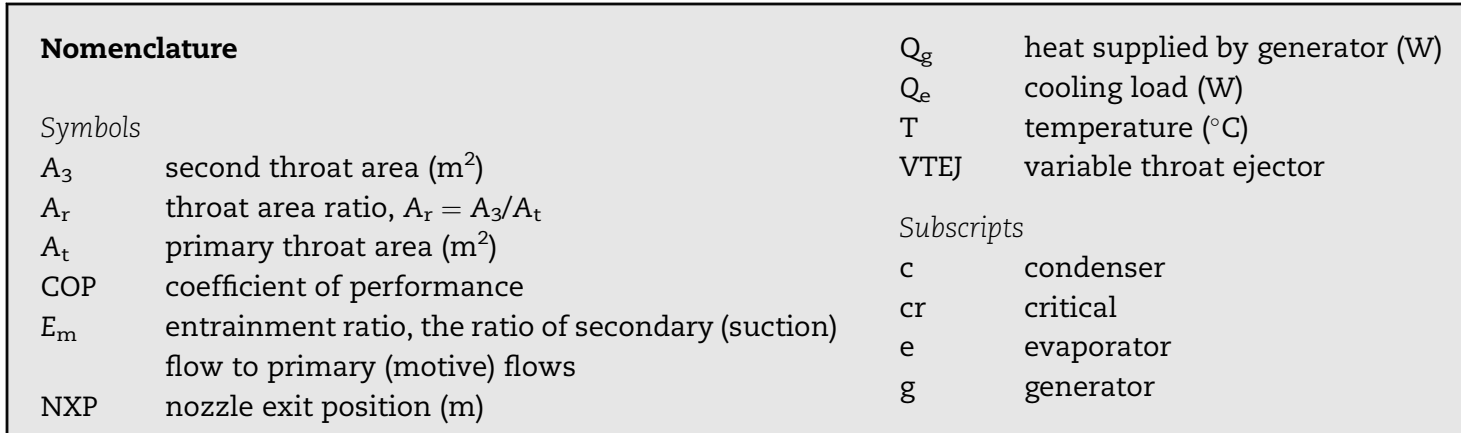

temperatures, such as the generator temperature, evaporator temperature, and condenser temperature. To achieve optimum performance, the ejector of a refrigeration system should have a specific geometry for a specific operating condition. For this reason, a conventional fixed geometry ejector that uses solar energy as a heat input cannot achieve its optimum performance. To optimize the refrigeration system, it is logical to make the ejector geometry adjustable to accommodate changes in operating conditions.

A review of the available literature shows that the use of variable-geometry ejectors in refrigeration systems can result in optimum performance over a wide range of operating conditions. Sun (1996) used a one-dimensional (1-D) ejector theory to investigate this concept. Ejectors have traditionally been designed and analyzed based on the classical 1-D gas dynamic theory (Alexis and Katsanis, 2004; Huang et al., 1985). With this approach, losses in the primary nozzle, secondary nozzle, mixing chamber and diffuser are considered by assuming respective subcomponent efficiencies. These loss coefficients, which depend on the ejector geometries, are empirical and can be determined by correlation with experimental data (Huang and Chang, 1999; Zhu et al., 2007). To this end, the present paper focuses on developing an appropriate approach to optimize the ejector geometry in a twodimensional (2-D) geometry.

To simulate the ejector flow in a more realistic way than with 1-D theory, various types of ejectors have been studied by CFD recently (Bartosiewicz et al., 2005; Desevaux and Aeschbacher, 2002; Desevaux et al., 2004; Rusly et al., 2005). Pianthong et al. (2007) showed that CFD is an efficient and accurate tool that provides sufficiently detailed information to design ejectors. Therefore, to improve ejector performance, this study proposes a variable throat ejector (VTEJ) and analyzes its performance using CFD simulation. Moreover, Kim et al. (2006) experimentally and numerically showed that a variable throat ejector can improve ejector efficiency in automotive hydrogen fuel cell systems. Their design varies the ejector throat area ratio as the operating conditions change. However, they failed to address the optimum ejector geometry. They used a needle-like cylinder cone intruding from the downstream into the primary throat section to change the throat area. However, the interaction of supersonic flow with the needle in the downstream may generate a complex shock wave. In addition, the cross-sectional area of the needle limits the flow rate of the refrigerant passing through the ejector, which may adversely affect performance of the ejector.
In this study, the analyzed VTEJ contains a spindle with a variable cross section along the axis. To minimize the influence of the intruding spindle, the spindle is inserted into the primary nozzle from the upstream side (Ma et al., 2010; Varga et al., 2009; Zhang et al., 2010). Thus, adjusting the position of the spindle changes the primary throat area. This controlled spindle modification can accommodate an unsteady solar heat supply. The main objective of this study is to numerically investigate the capability of the VTEJ to operate at optimum performance over a wide range of operating temperatures.

\section{Method}

\subsection{Assumption}

Fluid flow in the VTEJ is typically compressible and turbulent. To evaluate the variables in the fluid field, this study employs the $\mathrm{k}-\varepsilon$ turbulence model to describe the turbulent behavior in the VTEJ. In addition, we focus on the 2-D steady flow analysis. This study applies the following operating conditions: (1) a generation temperature, $T_{g}$, varying between $90^{\circ} \mathrm{C}$ and $110^{\circ} \mathrm{C}$, (2) a condenser temperature, $\mathrm{T}_{\mathrm{c}}$, exceeding $35^{\circ} \mathrm{C}$, and (3) an evaporator temperature, $\mathrm{T}_{\mathrm{e}}$, varying between $12^{\circ} \mathrm{C}$ and $20^{\circ} \mathrm{C}$. The working fluid is R245fa (Huang et al., 2011). Heat transfer through the walls of VTEJs is neglected.

Table 1 and Fig. 1 show the dimensions of the proposed ejector. To improve the $E_{m}$, the ejector has a converging angle in the mixing chamber (Zhu et al., 2009). The nozzle exit position (NXP) was chosen by simulation to achieve a greater $E_{m}$ (Chunnanond and Aphornratana, 2004; Pianthong et al., 2007; Rusly et al., 2005; Varga et al., 2009; Zhu et al., 2009). Different throat area ratios, $A_{r}=A_{3} / A_{t}$ (the ratio of the second throat area, $A_{3}$, to the primary throat area, $A_{t}$ ), ranging from 5.7 to 12.0, were simulated.

A commercial CFD package, FLUENT 6.3, was used to design the ejector. The ejector was simulated by a 2-D axisymmetric solver. Pianthong et al. (2007) found that the results yielded in good agreement with experiments and three-dimensional simulations, thus this axi-symmetry

\section{Table 1a - Ejector dimensions, unit: $\mathbf{m m}$.}

\begin{tabular}{ccccccccccc} 
NXP & d1 & L1 & ds & Ls & d2 & L2 & d3 & L3 & dd & Ld \\
\hline 30 & 13.80 & 41.3 & 70 & 36.3 & 22.8 & 28.7 & 19 & 100 & 35 & 115 \\
\hline
\end{tabular}


Table $\mathbf{1 b}$ - Ejector dimensions, unit: $\mathbf{m m}$.

\begin{tabular}{lccc}
$A_{\mathrm{r}}$ & $A_{3}$ & VTEJ_A & Move forward \\
\hline 7.2 & 283.385 & 39.359 & 12.838 \\
9.4 & 283.385 & 30.149 & 20.436 \\
12 & 283.385 & 23.615 & 24.431 \\
\hline
\end{tabular}

assumption is reasonable (Pianthong et al., 2007). The mesh was made of triangular elements, but quadrilateral elements within the boundary layer near the wall. The complex flow structure in the entrainment section, which is characterized by the interaction of the shock wave and boundary layer, requires a denser grid. The shock wave location varies with respect to the change of operating conditions so that the adaptive mesh was applied in the vicinity of shock. The realizable k- $\varepsilon$ model (Ji et al., 2010; Pianthong et al., 2007; Rusly et al., 2005; Sriveerakul et al., 2007; Varga et al., 2009; Wang and Dong, 2010) was selected to govern the turbulence characteristics, and the nonlinear governing equations were solved using the coupled-implicit solver. The near wall region was treated as a standard wall function. The working fluid was assumed to be an ideal gas. Other properties were remained constant throughout the simulation. All of the boundary conditions were set as pressure boundary conditions.

\subsection{Experimental setup}

An ejector test rig with a cooling capacity of $10.5 \mathrm{~kW}(3 \mathrm{RT})$ was made to perform the experiments. Details of the experimental setup are available in Huang et al. (2011). The ejector test rig equipment included the following nine major components: an experimental ejector, a generator, an evaporator, a condenser, a receiver-subcooler, a float regulating valve, a gear-type feed pump, a cooling tower and a control panel equipped with different measurement instrumentation. The generator and evaporator were designed in a cylinder shape using glass level gauges for liquid level observation. The working fluid in the generator was heated by two $13 \mathrm{~kW}$ electric heaters that were separately controlled. Heat energy was directly transferred to the evaporator by two $6 \mathrm{~kW}$ electric heaters to simulate the evaporator cooling load. The condenser was a conventional shell-and-tube heat exchanger with glass level gauge, cooled by water supplied from the cooling tower with a rejected heat capacity of $52 \mathrm{~kW}$. The receiver-subcooler was a specially designed shell-and-coil type vertical vessel cooled by water taken from the cooling tower. It was equipped with a level gauge and level transmitter for liquid level observation and

a

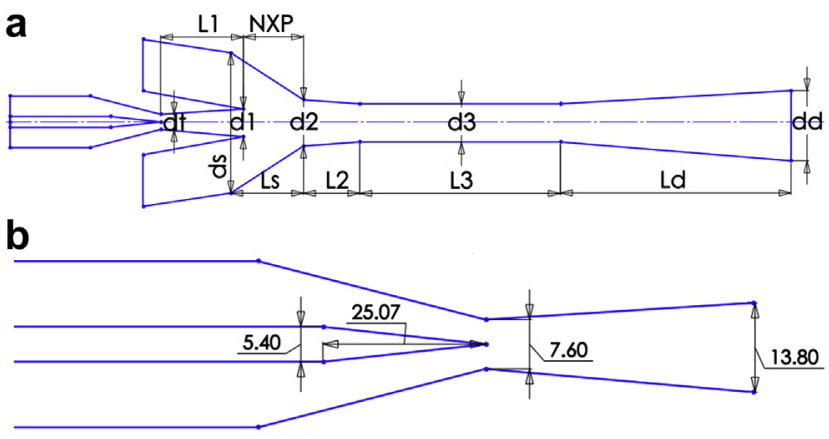

Fig. 1 - a. Ejector geometry. b. Ejector geometry. control. A hydraulic gear-type pump driven by three-phased variable speed electric motor was used as the generator feed pump. Primary and secondary flow rates were measured by gear-type flow meters. Control panel equipped with different instrumentations and other various standard components of refrigeration machine were also used in the construction of the ejector test rig. A PC-based monitoring and control system was developed for the ejector test rig. The data were sampled by a data acquisition system every $10 \mathrm{~s}$. Pressures, temperatures, primary and secondary flow rates, electric power consumptions and other required data were recorded and the results were calculated. This enabled the main performances to be determined in a steady state condition of system operation.

\subsection{Grid independent test}

Table 2 shows the results of a grid independence test for one of the proposed ejectors with an area ratio of $8.6, \mathrm{~T}_{\mathrm{g}}=100{ }^{\circ} \mathrm{C}$, and $\mathrm{T}_{\mathrm{e}}=15^{\circ} \mathrm{C}$. It shows only a slight change in the $E_{\mathrm{m}}$, cooling load $\left(\mathrm{Q}_{\mathrm{e}}\right)$, and COP as the cells of the mesh increase. Consequently, to conserve computing time, all of the simulations were performed with approximately 50,000 cells.

\subsection{Validation}

An ejector test rig was made to perform the experiments. Details of the experimental setup are available in Huang et al. (2011). Table 3 shows 27 CFD results with different area ratios at various operating conditions compared with the experimental data. This table shows that the difference of $E_{\mathrm{m}}$, cooling loads $\left(Q_{e}\right)$, and COP for most cases is within $10 \%$. However, large area ratios exhibit some fluctuation in the critical condenser temperature. This discrepancy may be caused by misalignment of the spindle in the primary nozzle, which controls the area ratios. By experimentally measuring the eccentricity of the spindle supports that mal-alignment causes fluctuation in the critical condenser temperature. Further investigation is needed to understand the mal-alignment effect. These results show that the CFD method can accurately predict the performance of the proposed ejectors.

\section{Results and discussion}

This work firstly discusses the performances of $E_{m}$ and COP for fixed-throat-area ejectors in section 3.1, in which the throat area ratio is considered. Secondly, the performance of $E_{\mathrm{m}}$ and COP for VTEJs are evaluated in sections 3.2-3.5. The heat supply and the cooling load corresponding to different throat area ratio are then discussed. Restated, the presented results are all obtained numerically.

\begin{tabular}{lcccc}
\multicolumn{5}{l}{ Table 2 - Grid independent test. } \\
Cells of mesh & $\mathrm{T}_{\mathrm{cr}}\left({ }^{\circ} \mathrm{C}\right)$ & $E_{\mathrm{m}}(\%)$ & $\mathrm{Q}_{\mathrm{e}}(\mathrm{kW})$ & $\mathrm{COP}$ \\
\hline 39,592 & 37.6 & 50.3 & 3.91 & 0.372 \\
51,481 & 38.0 & 52.8 & 4.07 & 0.391 \\
75,526 & 38.0 & 52.6 & 4.06 & 0.389 \\
\hline
\end{tabular}


Table 3 - Comparison of numerical(CFD) and experimental(Exp) results.

\begin{tabular}{|c|c|c|c|c|c|c|c|c|c|c|}
\hline$A_{r}$ & $\mathrm{~T}_{\mathrm{g}}$ & $\mathrm{T}_{\mathrm{e}}$ & $\mathrm{T}_{\mathrm{cr}}(\mathrm{CFD})$ & $\mathrm{T}_{\mathrm{cr}}(\mathrm{Exp})$ & $E_{\mathrm{m}}(\mathrm{CFD})$ & $E_{\mathrm{m}}(\operatorname{Exp})$ & $\mathrm{Q}_{\mathrm{e}}(\mathrm{CFD})$ & $\mathrm{Q}_{\mathrm{e}}(\mathrm{Exp})$ & COP (CFD) & COP (Exp) \\
\hline 5.7 & 90 & 12 & 40.2 & 39.9 & 0.31 & 0.36 & 2.79 & 2.7 & 0.23 & 0.21 \\
\hline 5.7 & 90 & 15 & 40.4 & 40.0 & 0.37 & 0.40 & 3.30 & 3.5 & 0.28 & 0.27 \\
\hline 5.7 & 90 & 20 & 39.6 & 38.7 & 0.51 & 0.49 & 4.54 & 4.5 & 0.39 & 0.37 \\
\hline 6.5 & 90 & 12 & 37.4 & 35.0 & 0.38 & 0.41 & 3.05 & 3.2 & 0.28 & 0.27 \\
\hline 6.5 & 90 & 15 & 37.4 & 34.6 & 0.46 & 0.48 & 3.73 & 3.9 & 0.35 & 0.34 \\
\hline 6.5 & 90 & 20 & 36.3 & 35.5 & 0.58 & 0.57 & 4.69 & 4.9 & 0.45 & 0.44 \\
\hline 7.2 & 90 & 12 & 35.4 & 31.6 & 0.43 & 0.43 & 3.26 & 3.4 & 0.32 & 0.31 \\
\hline 7.2 & 90 & 15 & 35.2 & 33.6 & 0.52 & 0.50 & 3.97 & 4.0 & 0.40 & 0.38 \\
\hline 7.2 & 90 & 20 & 34.0 & 34.8 & 0.65 & 0.60 & 5.04 & 5.1 & 0.51 & 0.49 \\
\hline 7.5 & 100 & 12 & 40.6 & 38.7 & 0.36 & 0.38 & 3.05 & 3.1 & 0.26 & 0.26 \\
\hline 7.5 & 100 & 15 & 40.6 & 38.0 & 0.42 & 0.45 & 3.58 & 3.8 & 0.31 & 0.33 \\
\hline 7.5 & 100 & 20 & 40.6 & 38.8 & 0.56 & 0.54 & 4.85 & 4.4 & 0.42 & 0.39 \\
\hline 8.6 & 100 & 12 & 37.5 & 34.2 & 0.42 & 0.43 & 3.28 & 3.6 & 0.31 & 0.32 \\
\hline 8.6 & 100 & 15 & 37.5 & 34.5 & 0.50 & 0.52 & 3.91 & 4.0 & 0.37 & 0.37 \\
\hline 8.6 & 100 & 20 & 37.0 & 36.4 & 0.62 & 0.61 & 4.85 & 5.1 & 0.47 & 0.50 \\
\hline 9.4 & 100 & 12 & 35.3 & 32.2 & 0.49 & 0.45 & 3.47 & 3.7 & 0.36 & 0.34 \\
\hline 9.4 & 100 & 15 & 35.2 & 33.6 & 0.58 & 0.55 & 4.18 & 4.1 & 0.43 & 0.40 \\
\hline 9.4 & 100 & 20 & 33.9 & 34.8 & 0.71 & 0.68 & 5.21 & 5.2 & 0.54 & 0.53 \\
\hline 10.0 & 110 & 12 & 40.0 & 35.9 & 0.41 & 0.39 & 3.27 & 3.3 & 0.29 & 0.30 \\
\hline 10.0 & 110 & 15 & 39.8 & 35.9 & 0.47 & 0.47 & 3.79 & 3.8 & 0.34 & 0.35 \\
\hline 10.0 & 110 & 20 & 40.5 & 35.3 & 0.61 & 0.54 & 4.97 & 4.7 & 0.45 & 0.44 \\
\hline 11.2 & 110 & 12 & 37.2 & 33.6 & 0.48 & 0.48 & 3.44 & 3.4 & 0.34 & 0.33 \\
\hline 11.2 & 110 & 15 & 37.3 & 33.9 & 0.56 & 0.56 & 4.08 & 3.9 & 0.41 & 0.39 \\
\hline 11.2 & 110 & 20 & 36.0 & 34.2 & 0.67 & 0.66 & 4.93 & 4.9 & 0.49 & 0.50 \\
\hline 12.0 & 110 & 12 & 35.7 & 28.1 & 0.52 & 0.49 & 3.58 & 3.5 & 0.37 & 0.36 \\
\hline 12.0 & 110 & 15 & 35.0 & 28.4 & 0.62 & 0.60 & 4.27 & 4.0 & 0.45 & 0.42 \\
\hline 12.0 & 110 & 20 & 33.9 & 30.4 & 0.75 & 0.73 & 5.30 & 5.2 & 0.56 & 0.55 \\
\hline
\end{tabular}

\subsection{Performance of fixed-throat-area ejectors}

This section presents a discussion on the effects of generator temperature variations on ejector performance. The condenser and evaporator temperatures were kept at $35{ }^{\circ} \mathrm{C}$ and $15^{\circ} \mathrm{C}$, respectively. Three fixed area ratios of $7.2,9.4$, and 12.0 were analyzed. After examining the $E_{\mathrm{m}}$, COP, cooling load, and generator heat required, it is possible to illustrate the pros and cons caused by different area ratios. It is also possible to clarify why a variable throat ejector must be designed to avoid the inefficiency of fixed ejectors as the generator temperature varies under fluctuating solar irradiation.

Table 4 shows the performance of the ejector with the throat area ratio fixed at 7.2 as the generator temperature varies. This ejector operates as choked when the generator temperature is between 90 and $110^{\circ} \mathrm{C}$, with a small change in cooling load. This is because the secondary flow, entrained into the mixing chamber, does not change significantly with different generator temperatures at the choked state. The

Table 4 - Ejector performance with the throat area ratio fixed at 7.2, $\mathrm{T}_{\mathrm{c}}=35^{\circ} \mathrm{C}$, and $\mathrm{T}_{\mathrm{e}}=15^{\circ} \mathrm{C}$.

\begin{tabular}{lccccc}
$\mathrm{T}_{\mathrm{g}}\left({ }^{\circ} \mathrm{C}\right)$ & $\mathrm{A}_{\mathrm{r}}$ & $\mathrm{E}_{\mathrm{m}}$ & $\mathrm{Q}_{\mathrm{g}}(\mathrm{kW})$ & $\mathrm{Q}_{\mathrm{e}}(\mathrm{kW})$ & $\mathrm{COP}$ \\
\hline 90 & 7.2 & $57.0 \%$ & 9.82 & 4.27 & 0.43 \\
100 & 7.2 & $40.1 \%$ & 12.53 & 3.73 & 0.30 \\
110 & 7.2 & $33.6 \%$ & 15.72 & 3.43 & 0.24 \\
\hline
\end{tabular}

primary nozzle flow rate increases in conjunction with the generator temperature as the result of pressure increasing at the inlet of the primary nozzle. Therefore, it leads to an increase in the heat supply, $\mathrm{Q}_{\mathrm{g}}$, and decrease in $E_{\mathrm{m}}$ and COP. The table also shows that the heat required from the solar collector is the largest when the generator temperature is $110^{\circ} \mathrm{C}$. At this temperature the heat required is 1.60 times of that at the temperature of $90^{\circ} \mathrm{C}$.

To allow the ejector system with the throat area ratio fixed at 7.2 to operate at generator temperatures ranging from 90 to $110{ }^{\circ} \mathrm{C}$, the size of the solar collector must be determined based on the maximum heat needed, which is the one operating at the generator temperature of $110^{\circ} \mathrm{C}$ instead of $90^{\circ} \mathrm{C}$. For such a system, if the ejector system operates at $110^{\circ} \mathrm{C}$, the solar collector supplies just enough energy to evaporate the refrigerant. However, if the ejector system operates at less than $110^{\circ} \mathrm{C}$, the solar energy is in excess. The amount of heat required by the VTEJ operating at a generator temperature range of $90-110^{\circ} \mathrm{C}$, as discussed in the Section 3.2 , is the one for the fixed ejector operating at $90{ }^{\circ} \mathrm{C}$ instead of $110{ }^{\circ} \mathrm{C}$. The heat needed at $90^{\circ} \mathrm{C}$ is $60 \%$ less than that at $110^{\circ} \mathrm{C}$. Therefore, for this ejector system with a fixed throat area ratio of 7.2, the solar collector is overdesigned when the generator temperature is below $110^{\circ} \mathrm{C}$.

Table 5 shows the performance of the ejector with the throat area ratio fixed at 9.4 as the generator temperature varies. This system is unable to work under the choked condition when the generator temperature is $90{ }^{\circ} \mathrm{C}$ because its critical condenser temperature is lower than the operating temperature of $35^{\circ} \mathrm{C}$. The fluid in the mixing chamber then 
Table 5 - Performance of the ejector with the throat area ratio fixed at $9.4, \mathrm{~T}_{\mathrm{c}}=35^{\circ} \mathrm{C}$ and $\mathrm{T}_{\mathrm{e}}=15^{\circ} \mathrm{C}$.

\begin{tabular}{lllrrr}
$\mathrm{T}_{\mathrm{g}}\left({ }^{\circ} \mathrm{C}\right)$ & $A_{\mathrm{r}}$ & \multicolumn{1}{l}{$E_{\mathrm{m}}$} & $\mathrm{Q}_{\mathrm{g}}(\mathrm{kW})$ & $\mathrm{Q}_{\mathrm{e}}(\mathrm{kW})$ & $\mathrm{COP}$ \\
\hline 90 & 9.4 & \multicolumn{2}{l}{ Reversed flow } & & \\
100 & 9.4 & $60.8 \%$ & 9.65 & 4.36 & 0.45 \\
110 & 9.4 & $44.0 \%$ & 12.14 & 3.87 & 0.32 \\
\hline
\end{tabular}

flows back to the evaporator, placing the system in the failure state and producing zero cooling load. However, the system can operate under the choked condition when the generator temperature is between 100 and $110^{\circ} \mathrm{C}$, with a small variation in cooling load. Compared to the previous ejector in Table 4, which has a larger throat area (or smaller area ratio), the present ejector with smaller throat area (or larger area ratio) has a higher $E_{m}$ and COP. It also shows that the generator requires less heat and thus requires a smaller solar collector. In summary, an ejector system with a smaller throat area can achieve better performance and is more cost-effective, but has the downside that the operating temperature of the generator can only be between 100 and $110{ }^{\circ} \mathrm{C}$.

Table 6 shows the performance of the ejector with the throat area ratio fixed at 12.0 as the generator temperature varies. This system cannot operate under the choked condition when the generator temperature is between 90 and $100{ }^{\circ} \mathrm{C}$. It can only operate under the choked condition when the generator temperature rises to $110{ }^{\circ} \mathrm{C}$. Compared to the previous two ejectors with larger throat areas (Tables 4 and 5), the present ejector achieves the highest $E_{\mathrm{m}}$ and COP. This generator requires the least heat and the smallest solar collector. In summary, the ejector with the smallest throat area has the best performance and is the most cost-effective, but has the downside of the narrowest operating temperature for the generator.

In conclusion, for the ejector with a fixed throat area, the combination of a greater throat area and larger solar collector allows a wider range of generator-operating temperatures, but may be overdesigned and expensive. However, decreasing the throat area also decreases the operating range of the generator temperature. Thus, the fixed throat area ejector may be unsuitable to use solar energy as a heat source.

\subsection{Performance of the VTEJ}

The proposed ejector has the ability to vary the throat area by inserting a spindle with a variable cross section into the primary nozzle. Different throat areas can be obtained by adjusting the position of the spindle. The throat area ratio for each generator temperature is based on the results obtained from the fixed throat ejectors in Section 3.1.

Table 6 - Performance of the ejector with the throat area ratio fixed at 12.0, $\mathrm{T}_{\mathrm{c}}=35^{\circ} \mathrm{C}$ and $\mathrm{T}_{\mathrm{e}}=15^{\circ} \mathrm{C}$.

\begin{tabular}{lclrll}
$\mathrm{T}_{\mathrm{g}}\left({ }^{\circ} \mathrm{C}\right)$ & $\mathrm{A}_{\mathrm{r}}$ & $E_{\mathrm{m}} \quad \mathrm{Q}_{\mathrm{g}}(\mathrm{kW})$ & $\mathrm{Q}_{\mathrm{e}}(\mathrm{kW})$ & $\mathrm{COP}$ \\
\hline 90 & 12.0 & Reversed flow & & \\
100 & 12.0 & $\begin{array}{l}\text { Reversed flow } \\
68.3 \% \quad 9.4\end{array}$ & 4.67 & 0.50 \\
110 & 12.0 & $68.3 \%$ & 9.4 & & \\
\hline
\end{tabular}

Table 7 - Performance of the ejector with variable throat area, $T_{c}=35^{\circ} \mathrm{C}$ and $T_{e}=15^{\circ} \mathrm{C}$.

\begin{tabular}{lrcccc}
$\mathrm{T}_{\mathrm{g}}\left({ }^{\circ} \mathrm{C}\right)$ & $\mathrm{A}_{\mathrm{r}}$ & $E_{\mathrm{m}}$ & $\mathrm{Q}_{\mathrm{g}}(\mathrm{kW})$ & $\mathrm{Q}_{\mathrm{e}}(\mathrm{kW})$ & $\mathrm{COP}$ \\
\hline 90 & 7.2 & $57.0 \%$ & 9.82 & 4.27 & 0.43 \\
100 & 9.4 & $60.8 \%$ & 9.65 & 4.36 & 0.45 \\
110 & 12.0 & $68.3 \%$ & 9.42 & 4.67 & 0.50 \\
\hline
\end{tabular}

Table 7 shows the throat area ratio to be adjusted with respect to the generator temperature and its corresponding performance for the VTEJ. The critical condenser temperature remains above $35^{\circ} \mathrm{C}$. Thus, the system is able to operate under the choked condition for generator temperatures ranging from 90 to $110^{\circ} \mathrm{C}$. The heat supply and the cooling load for the VTEJ remain almost unchanged as the generator temperature varies, and the heat supply is almost as low as that of the fixed throat ejector with an area ratio of 7.2 at a generator temperature of $90{ }^{\circ} \mathrm{C}$. Therefore, the superiority of the variable throat ejector over the fixed throat ejector is readily apparent.

In addition, the adjustable spindle in the primary nozzle greatly affects the pressure at the outlet of the primary nozzle. As generator temperature is large, a large $A_{r}$ decreases the pressure at the outlet of the primary nozzle, which develops the primary flow to the trends of over-expansion. On the other hand, at a large generator temperature, fixed throat ejector trends to under-relaxation because a large pressure occurs at the outlet of the primary nozzle, which harms to COP. Similarly, an over-expansion flow can be observed at a large $A_{r}$ when $T_{e}$ is large, and at a small $A_{r}$ when $T_{C}$ is small. Therefore, the performance of VTEJ is excellent.

\subsection{Effect of generator temperature on optimum VTEJ performance}

Fig. 2 shows the COP performance of three fixed throat area ejectors at varying generator temperatures. For any ejector, an optimum generator temperature exists at which the COP is the maximum. This finding is in agreement with that of Yapicl et al. (2008). When the generator temperature exceeds the optimal value, an increase in the primary flow rate leads to an increase in the heat supply to the generator, and thus, a decrease in the COP. However, when the generator

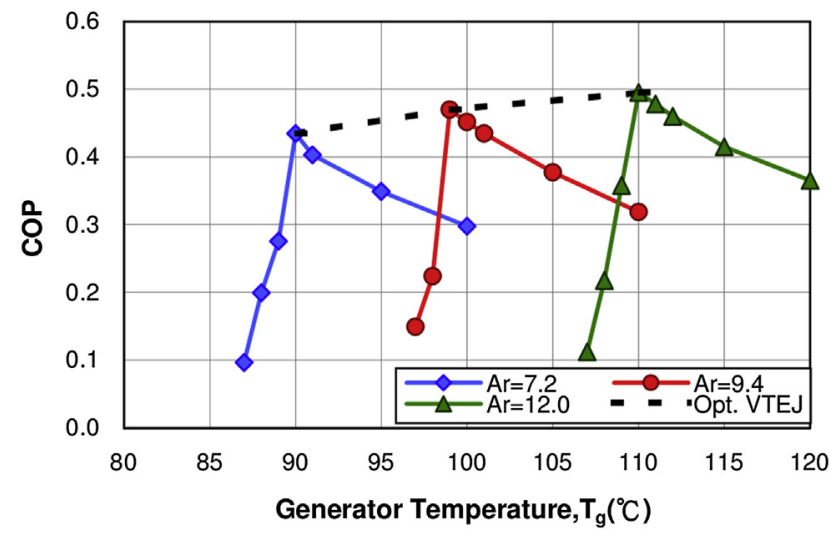

Fig. 2 - Comparison of the COP for the variable and fixed throat ejector, $\mathrm{T}_{\mathrm{c}}=35^{\circ} \mathrm{C}$ and $\mathrm{T}_{\mathrm{e}}=15^{\circ} \mathrm{C}$. 


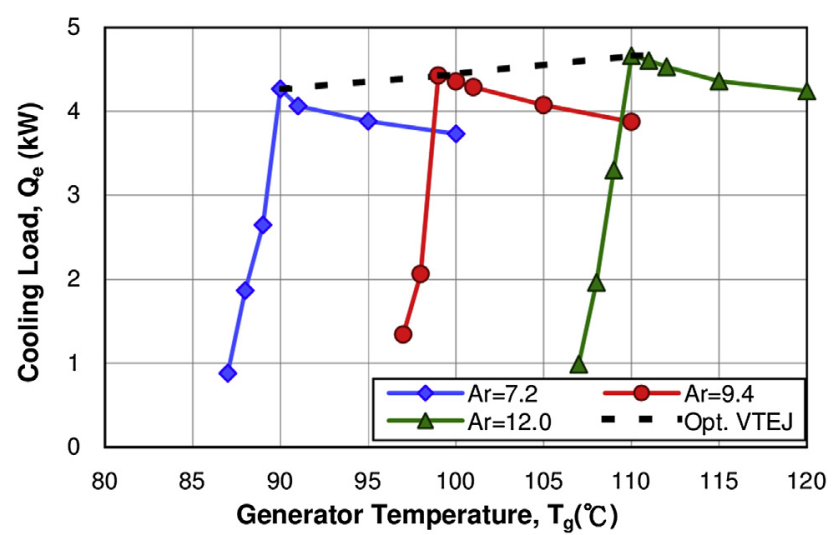

Fig. 3 - Comparisons of cooling load for the variable and fixed throat ejector, $\mathrm{T}_{\mathrm{c}}=35^{\circ} \mathrm{C}$ and $\mathrm{T}_{\mathrm{e}}=15^{\circ} \mathrm{C}$.

temperature is lower than the optimum value, the operating condition may change from the choked to unchoked condition or even have a reversed flow, resulting in a rapid drop in the COP.

The black dotted curve in Fig. 2 is the line connecting the maximum COP with various throat areas. This is the optimum performance curve that gives the relationship between COP and throat area as the generator temperature varies for the VTEJ. The throat area should be adjusted according to this relationship to operate the VTEJ at optimal performance as the generator temperature varies. Fig. 2 also shows that as the generator temperature increases, the optimal COP increases, and the throat area ratio should be increased to achieve optimum performance.

Figs. 3 and 4 show comparisons of the cooling load and heat supply for fixed and variable throat ejectors. The black dotted curves in Figs. 3 and 4 show the optimum cooling load and heat supply as a function of the generator temperature for the VTEJ.

\subsection{Effect of condenser temperatures on optimum VTEJ performance}

Fig. 5 shows the COP as a function of the condenser temperatures for three fixed throat area ejectors. The COP remains at its peak value, regardless of a change in the condenser

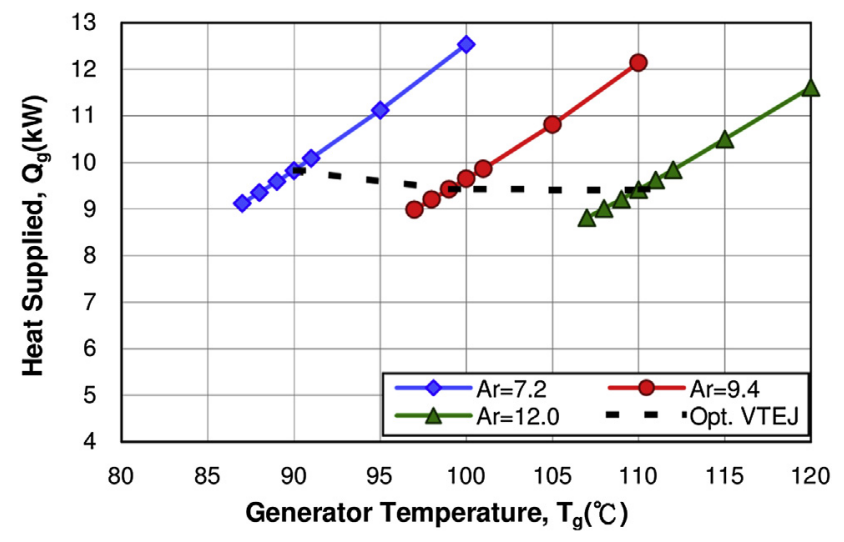

Fig. 4 - Comparisons of heat supply for the variable and fixed throat ejector, $\mathrm{T}_{\mathrm{c}}=35^{\circ} \mathrm{C}$ and $\mathrm{T}_{\mathrm{e}}=15^{\circ} \mathrm{C}$.

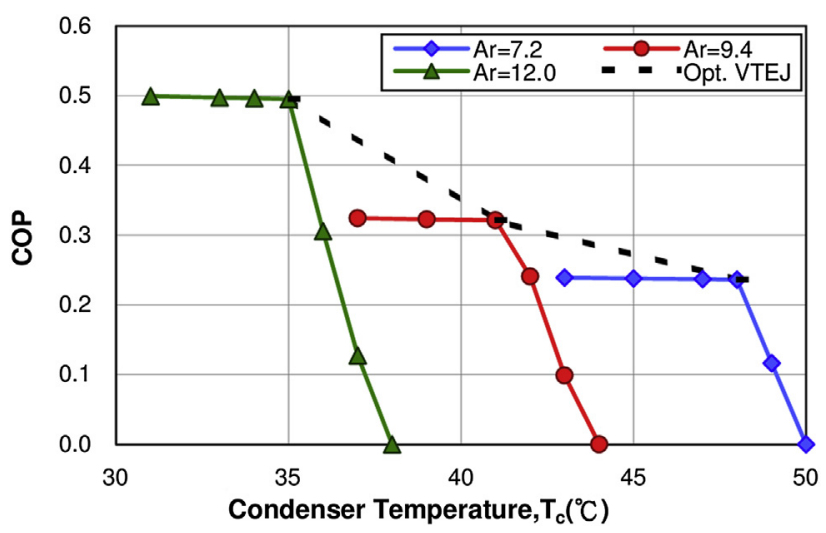

Fig. 5 - COP performance of different $A_{\mathrm{r}}$ values at $\mathrm{T}_{\mathrm{g}}=110^{\circ} \mathrm{C}$ and $\mathrm{T}_{\mathrm{e}}=15^{\circ} \mathrm{C}$.

temperature when the ejector operates in the choked state. When the condenser temperature falls below $35^{\circ} \mathrm{C}$, all three ejectors operate in the choked state, and a higher throat area ratio leads to a higher COP. It can be seen that the $A_{r}=12.0$ ejector has the highest COP. When the condenser temperature is between 35 and $41{ }^{\circ} \mathrm{C}$, the $A_{r}=12.0$ ejector operates in the unchoked state, resulting in a rapid drop in the COP, whereas the other two ejectors, with smaller throat area ratio, continue to operate in the choked state. Thus, the ejector with $A_{r}=9.4$ possesses the highest COP among these three ejectors. When the condenser temperature is between 41 and $48^{\circ} \mathrm{C}$, the ejectors with $A_{r}=9.4$ and 12.0 operate in the reversed state, meaning that the fluid in the evaporator chamber cannot be sucked into the mixing chamber, causing the ejectors to fail. Therefore, the ejector with $A_{r}=7.2$ only operates in the choked state.

Fig. 6 shows the cooling load as a function of condenser temperatures for various throat area ratios. Because the condenser temperature is lower than the critical temperature, the cooling load varies only slightly. In other words, for a specific throat area ratio, the cooling load remains at almost its peak value, regardless of a change in the condenser temperature when the ejector operates in the choked state.

In conclusion, as the condenser temperature varies, adjusting the throat area may achieve the highest COP and cooling load if the ejector operates in the choked state,

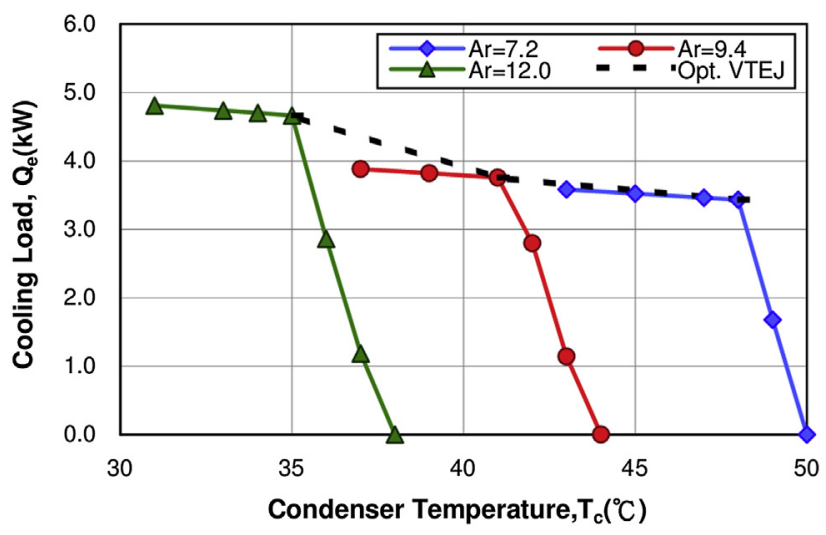

Fig. 6 - Cooling load of different $A_{r}$ values at $T_{g}=110{ }^{\circ} \mathrm{C}$ and $T_{e}=15^{\circ} \mathrm{C}$. 




Fig. 7 - Optimum entrainment ratio at different operating temperatures.

meaning that the condenser temperature is less than the critical temperature. Therefore, it is reasonable to assume that the optimum condenser temperature is the critical condenser temperature for an ejector with a specific throat area. The black dotted curve in Figs. 5 and 6 connects all the optimum points. These are the optimum COP curves for a VTEJ operating with an appropriate throat area ratio adjusted according to the variation in the condenser temperatures. It also shows that as the condenser temperature decreases, the throat area ratio should be increased to achieve the optimum COP, and vice versa.

The effect of evaporator temperature on optimum VTEJ performance can be discussed in the same manner. The next section presents the results.

\subsection{Optimization of the VTEJs}

The proposed solar-driven ejector refrigeration system is designed to operate at $\mathrm{T}_{\mathrm{g}}=90-110{ }^{\circ} \mathrm{C}, \mathrm{T}_{\mathrm{e}}=8-20^{\circ} \mathrm{C}$, and

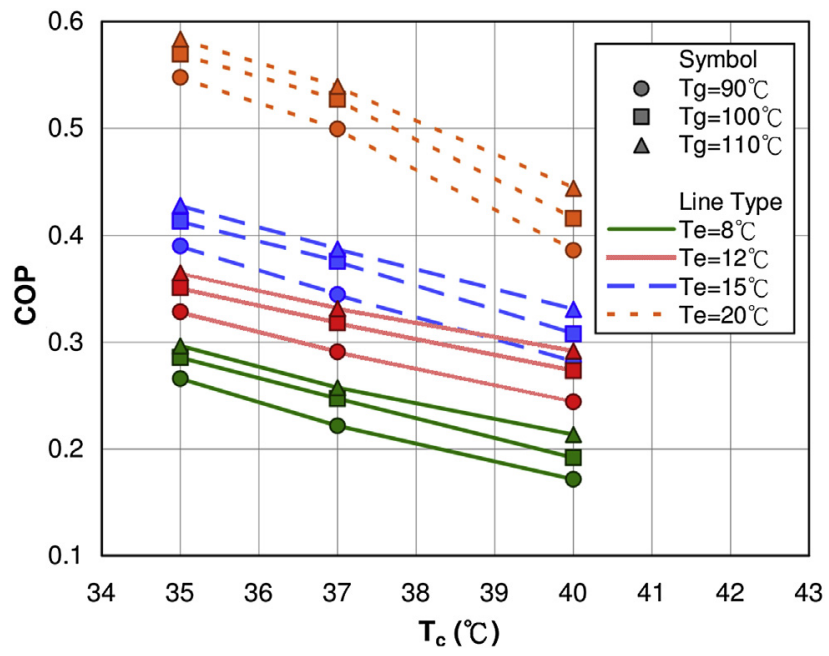

Fig. 8 - Optimum COP at different operating temperatures.

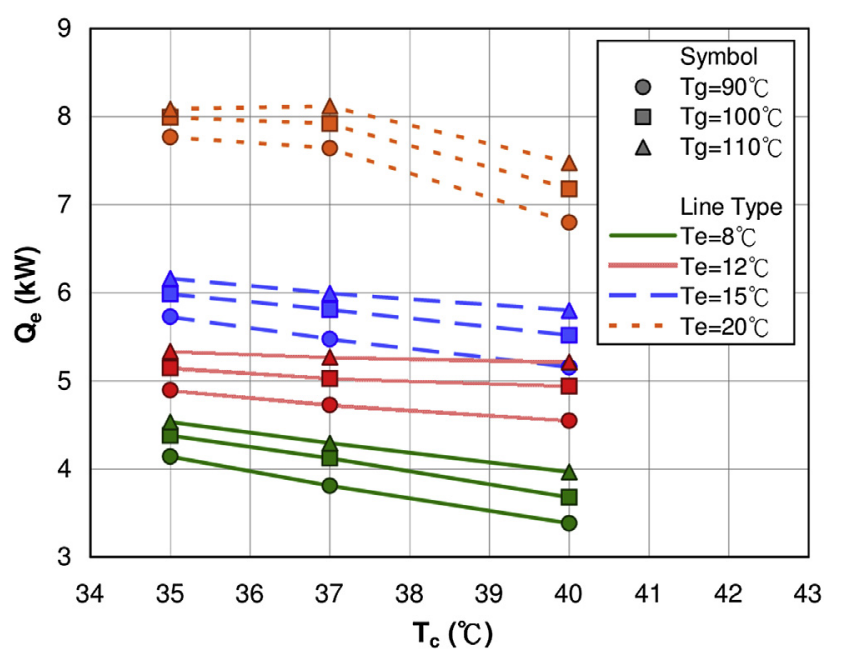

Fig. 9 - Optimum cooling load at different operating temperatures.

$\mathrm{T}_{\mathrm{C}}=35-40^{\circ} \mathrm{C}$. This section presents a discussion on the optimum operating performance of the VTEJ under these operating conditions. Figs. 7-9 respectively present the optimum $E_{\mathrm{m}}$, COP, and cooling load of the VTEJs. In these figures, the symbol represents the generator temperature, and the line type represents the evaporator temperature. Increasing the generator temperature and keeping the evaporator and condenser temperatures unchanged increases the COP, $E_{m}$, and cooling load. In addition, increasing the evaporator temperature but keeping the generator and condenser temperatures unchanged increases the COP, $E_{m}$, and cooling load.

In general, the $Q_{e}$ increases with the decreases of the $T_{c}$, as shown in Fig. 9. Section 3.4 reveals that to achieve the optimum COP, the throat area ratio $A_{t}$ should be increased as the condenser temperature $T_{C}$ decreases. That is because a small $A_{t}$ results in a large effective area and a large secondary flow. Notably, at $\mathrm{T}_{\mathrm{e}}=20^{\circ} \mathrm{C}$ and $\mathrm{T}_{\mathrm{g}}=110^{\circ} \mathrm{C}$, when $\mathrm{T}_{\mathrm{C}}$ increases from $35^{\circ} \mathrm{C}$ to $37^{\circ} \mathrm{C}, \mathrm{Q}_{\mathrm{e}}$ increases slightly before drops down with the increase of $T_{C}$, which is different from other data. As mentioned in Sec. 3.4, the throat area ratio $A_{t}$ at $T_{C}=35{ }^{\circ} \mathrm{C}$ is smaller than that at $\mathrm{T}_{\mathrm{C}}=37^{\circ} \mathrm{C}$, which indicates a smaller secondary flow. Therefore, backflow occurs at $\mathrm{T}_{\mathrm{C}}=35^{\circ} \mathrm{C}$ due to a large $T_{e}$ and a small $A_{t}$ on the flow can augment the overexpansion flow in the primary flow. Thus, backflow decreases the $Q_{e}$ at $T_{c}=35^{\circ} \mathrm{C}$ compared to that for $T_{C}=37^{\circ} \mathrm{C}$.

In addition to the optimum $E_{\mathrm{m}}$, COP, and the cooling load for optimum VTEJs, the corresponding optimum throat area ratio can also be obtained. This paper obtains the linear regression parameters by introducing the respective formulas on a Microsoft Excel worksheet. A regressive equation that provides a relation between $A_{r}$ and the operating temperatures is given below.

$$
\begin{aligned}
A_{r_{-} o p t}= & 0.717 T_{g}-0.02 T_{e}+0.702 T_{c}+0.00204 T_{g} T_{e}-0.01185 T_{g} T_{c} \\
& -0.00257 T_{e} T_{c}-43.95
\end{aligned}
$$

The maximum error of the equation is $3.0 \%$. Fig. 10 shows the relationship of the optimum throat area ratio at different 


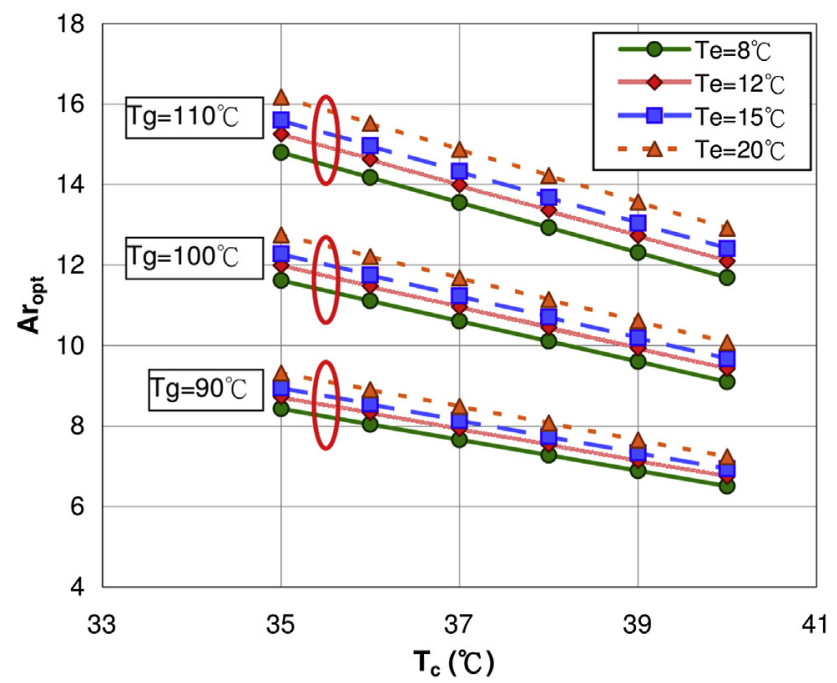

Fig. 10 - Optimum throat area ratios $\left(A_{r_{-} \text {opt }}\right)$ at different operating temperatures.

operating temperatures. It shows that as the condenser temperature increases, the throat area ratio decreases linearly when $\mathrm{T}_{\mathrm{g}}$ and $\mathrm{T}_{\mathrm{e}}$ are kept unchanged. The throat area ratio also decreases as the generator temperature increases or the evaporator temperature decreases. From a practical operating viewpoint, if the generator, evaporator, or condenser temperature changes, the throat area ratio can be adjusted using the regressive equation.

\section{Conclusions}

The operating temperature of the proposed solar-driven ejector refrigeration system may change according to solar irradiation. When the generator, evaporator, or condenser temperature changes, the conventional fixedthroat ejector may work expensively, and may even malfunction. To improve ejector performance, this study proposes a variable throat ejector and analyzes its performance using CFD simulations. This study presents the following conclusions.

An ejector with a greater throat area and larger solar collector allows a wider operating range of generator temperatures, but may be overdesigned and expensive. Conversely, decreasing the throat area limits the operating range of the generator temperature, and the resulting system may be unable to use solar energy as a heat source.

If the operating temperature varies, the variable throat ejector can be adjusted to the corresponding optimal throat area ratio. This allows the system to achieve optimal performance. This study presents a regressive equation that relates the optimum throat area ratio to the operating conditions at temperature ranges of $\mathrm{T}_{\mathrm{g}}=90-110{ }^{\circ} \mathrm{C}$, $\mathrm{T}_{\mathrm{e}}=8-20^{\circ} \mathrm{C}$, and $\mathrm{T}_{\mathrm{c}}=35-40^{\circ} \mathrm{C}$. From a practical operating viewpoint, if the generator, evaporator, or condenser temperature is known, the ejector can be adjusted to the corresponding optimal throat area ratio using the regressive equation.

\section{Acknowledgments}

This publication is based on the work supported by Award No.KUK-C1-014-12, made by King Abdullah, University of Science and Technology (KAUST), Saudi Arabia.

\section{R E F E R E N C E S}

Alexis, G.K., Katsanis, J.S., 2004. Performance characteristics of a methanol ejector refrigeration unit. Energy Conv. Manag. 45 (17), 2729-2744.

Bartosiewicz, Y., Aidoun, Z., Desevaux, P., Mercadier, Y., 2005. Numerical and experimental investigations on supersonic ejectors. Int. J. Heat Fluid Flow 26 (1), 56-70.

Chunnanond, K., Aphornratana, S., 2004. An experimental investigation of a steam ejector refrigerator: the analysis of the pressure profile along the ejector. Appl. Therm. Eng. 24 (2-3), 311-322.

Desevaux, P., Aeschbacher, O., 2002. Numerical and experimental flow visualizations of the mixing process inside an induced air ejector. Int. J. Turbo. Jet-Engines 19 (1-2), 71-78.

Desevaux, P., Mellal, A., de Sousa, A., 2004. Visualization of secondary flow choking phenomena in a supersonic air ejector. J. Visualization 7 (3), 249-256.

Huang, B.J., Chen, S.L., Petrenko, V.O., Shestopalov, K.O., 2011. Theoretical and experimental investigation of the performance characteristics of an ejector cooling machine operating with refrigerant R245fa. In: The 23rd IIR International Congress of Refrigeration, August 21-26, 2011, Prague, Czech Republic.

Huang, B.J., Chang, J.M., 1999. Empirical correlation for ejector design. Int. J. Refrigeration 22 (5), 379-388.

Huang, B.J., Jiang, C.B., Hu, F.L., 1985. Ejector performancecharacteristics and design analysis of jet refrigeration system. J. Eng. Gas. Turbines Power-Trans. ASME 107 (3), 792-802.

Ji, M., Utomo, T., Woo, J., Lee, Y., Jeong, H., Chung, H., 2010. CFD investigation on the flow structure inside thermo vapor compressor. Energy 35 (6), 2694-2702.

Kim, H., Lee, J., Setoguchi, T., Matsuo, S., 2006. Computational analysis of a variable ejector flow. J. Therm. Sci. 15 (2), 140-144.

Ma, X., Zhang, W., Omer, S.A., Riffat, S.B., 2010. Experimental investigation of a novel steam ejector refrigerator suitable for solar energy applications. Appl. Therm. Eng. 30 (11-12), 1320-1325.

Pianthong, K., SeehanaM, W., Behnia, M., SriveerakUl, T., Aphornratana, S., 2007. Investigation and improvement of ejector refrigeration system using computational fluid dynamics technique. Energy Conv. Manag. 48 (9), 2556-2564.

Rusly, E., Aye, L., Charters, W.W.S., Ooi, A., 2005. CFD analysis of ejector in a combined ejector cooling system. Int. J. Refrigeration 28 (7), 1092-1101.

Sriveerakul, T., Aphornratana, S., Chunnanond, K., 2007. Performance prediction of steam ejector using computational fluid dynamics: Part 2. Flow structure of a steam ejector influenced by operating pressures and geometries. Int. J. Therm. Sci. 46 (8), 823-833.

Sun, D.W., 1996. Variable geometry ejectors and their applications in ejector refrigeration systems. Energy 21 (10), 919-929.

Varga, S., Oliveira, A.C., Diaconu, B., 2009. Influence of geometrical factors on steam ejector performance $-\mathrm{a}$ numerical assessment. Int. J. Refrigeration 32 (7), 1694-1701.

Wang, X.D., Dong, J.L., 2010. Numerical study on the performances of steam-jet vacuum pump at different operating conditions. Vacuum 84 (11), 1341-1346. 
Yapıcı, R., Ersoy, H.K., Aktoprakoğlu, A., Halkacı, H.S., Yiğit, O., 2008. Experimental determination of the optimum performance of ejector refrigeration system depending on ejector area ratio. Int. J. Refrigeration 31 (7), 1183-1189.

Zhang, K., Shen, S., Yang, Y., 2010. Numerical investigation on performance of the adjustable ejector. Int. J. Low-Carbon. Technol. 5 (2), 51-56.
Zhu, Y.H., Cai, W.J., Wen, C.Y., Li, Y.Z., 2007. Shock circle model for ejector performance evaluation. Energy Conv. Manag. 48 (9), 2533-2541.

Zhu, Y.H., Cai, W.J., Wen, C.Y., Li, Y.Z., 2009. Numerical investigation of geometry parameters for design of high performance ejectors. Appl. Therm. Eng. 29 (5-6), 898-905. 